\title{
First annular-ring coupled structure cavity for the Japan Proton Accelerator Research Complex linac
}

\author{
Hiroyuki Ao, ${ }^{*}$ Akira Ueno, Koichiro Hirano, Hiroyuki Asano, \\ Takatoshi Morishita, Kazuo Hasegawa, and Yoshishige Yamazaki \\ J-PARC Center, Japan Atomic Energy Agency, 2-4, Shirakata-shirane, Tokai, Naka, Ibaraki, 319-1195, Japan
}

(Received 15 December 2011; published 24 May 2012)

\begin{abstract}
The first annular-ring coupled structure (ACS) cavity for the Japan Proton Accelerator Research Complex (J-PARC) linac has been developed in order to confirm and establish its fabrication processes. This cavity includes 34 accelerating cells, which is 3.4 times as many as the prototype cavity (buncher) of the J-PARC ACS. The cell frequencies before brazing were tuned within the required accuracies. After brazing, the accelerating- and coupling-mode frequencies were 972.19 and $972.63 \mathrm{MHz}$ on average, respectively, which were higher than the operating frequency of $972 \mathrm{MHz}$. Although the acceleratingmode frequency can be corrected to $972 \mathrm{MHz}$ using adjustable plungers, these frequency errors adversely affected the on-axis electric field. This cavity was successfully conditioned up to $1.6 \mathrm{MW}$. This power corresponds to an accelerating field of $4.7 \mathrm{MV} / \mathrm{m}$, which is $10 \%$ higher than the design value of 4.2 MV/m. In order to find the issue caused by the excited coupling cells, this cavity was also conditioned at the higher and lower frequencies that were detuned from the operating frequency of $972 \mathrm{MHz}$. Here we present the frequency tuning processes, the low-level rf measurements, and the high-power test results. We also discuss the most reasonable scenario for frequency tuning in future work.
\end{abstract}

DOI: 10.1103/PhysRevSTAB.15.051005

PACS numbers: 29.20.Ej

\section{INTRODUCTION}

An annular-ring coupled structure (ACS) [1] is a $\pi / 2$ mode structure, a category that includes on-axis coupled structures [2], side coupled structures (SCSs) [3], and diskand-washer structures [1] as well-known examples. Table I shows the comparison of the main parameters and features between the SCS and the ACS. Compared to a commonly used SCS, the main parameters of the ACS are comparable to those of the SCS, and the ACS has also many desirable features due to its axial symmetry (see Fig. 1). The negligible small dipole component of the accelerating field is a main feature of the ACS.

Beam loss is a critical issue for high-intensity proton accelerators. However, understanding all of the sources of beam loss is difficult. Therefore, the possible causes of beam loss are preferable to be minimized as much as possible.

One of the possible causes, the deviation of an accelerating field from axial symmetry, may cause emittance growth and/or halo formation. The accelerating field mixed with a dipole mode kicks a beam in a transverse direction. In the SCS, the orientation of the slots is determined (arranged alternately to the beam axis) to cancel out the transverse kick in the total cavity. However, the cancellation of the transverse effects is not perfect for a nonrelativistic beam.

\footnotetext{
*hiroyuki.ao@j-parc.jp

Published by the American Physical Society under the terms of the Creative Commons Attribution 3.0 License. Further distribution of this work must maintain attribution to the author(s) and the published article's title, journal citation, and DOI.
}

The field distortion due to coupling slots causes a emittance growth in high-intensity linacs [7].

The smooth surface of the ACS, which is obtained using an ultraprecision lathe, realizes a high $Q$ value and a high discharge limit. The cell frequency of the ACS also can be tuned using an ultraprecision lathe, i.e., it can be controlled numerically, which becomes an advantage in the future mass production of the ACS. The above-mentioned features are the main reasons why the ACS was adopted and developed for the Japan Proton Accelerator Research Complex (J-PARC) linac.

In contrast to that of the SCS, the accelerating-cell frequency of the ACS is hard to tune after assembly. The accelerating cell of the SCS can be handled from outside, whereas that of the ACS is surrounded by the coupling cell (see Fig. 1). Thus, the cell frequency has to be tuned before brazing, taking into account the frequency shift due to brazing.

The first ACS prototype cavity (buncher 1) for use in the J-PARC linac was developed to confirm the feasibility of its fabrication and frequency tuning, as well as to confirm that it can meet the performance required by the J-PARC linac [8]. After that, another prototype cavity (buncher 2) was also fabricated; however, these prototype ACSs were buncher cavities that included only 10 accelerating cells in total.

As the next step, fabrication and testing of a full-fledged ACS cavity that includes 34 accelerating cells in total was planned. The purpose and outline of the development of the present cavity are the following: (i) We have to be able to evaluate frequency shifts due to brazing, since the cell 
TABLE I. Comparison between a side coupled structure (SCS) and an annular-ring coupled structure (ACS).

\begin{tabular}{|c|c|c|}
\hline Main parameter & SCS & ACS \\
\hline Energy region & \multicolumn{2}{|c|}{$\beta>0.4$} \\
\hline Peak current $^{\mathrm{a}}$ & $38 \mathrm{~mA}$ & $50 \mathrm{~mA}$ \\
\hline Shunt impedance ${ }^{\mathrm{b}}$ & \multirow{2}{*}{\multicolumn{2}{|c|}{$\begin{array}{l}\text { Comparable } \\
\text { Comparable }\end{array}$}} \\
\hline Coupling factor ${ }^{\mathrm{c}}$ & & \\
\hline Main feature & SCS & ACS \\
\hline Dipole component of an accelerating field ${ }^{\mathrm{c}}$ & Approximately $1 \%$ & Negligible small \\
\hline $\begin{array}{l}\text { Machining and frequency tuning using an } \\
\text { ultraprecision lathe }\end{array}$ & Not available & Available \\
\hline
\end{tabular}

${ }^{a}$ Here, we show examples of proton accelerators. In this row, $38 \mathrm{~mA}$ of the SCS and $50 \mathrm{~mA}$ of the ACS are design values of Spallation Neutron Source (Oak Ridge) and J-PARC, respectively. The maximum intensities limited by the distortion of the accelerating field due to beam loading are comparable, since it depends on the coupling factor (group velocity) of the structure.

${ }^{\mathrm{b}}$ See Ref. [4] for detailed information.

${ }^{\mathrm{c}}$ See Ref. [5] for detailed information.

frequency has to be tuned before brazing taking into account the frequency shift. In the case of bunchers 1 and 2 , the frequency shifts were scattered, and the frequency shift may depend upon the number of cells. The difference between the frequency shifts of the prototypes and the

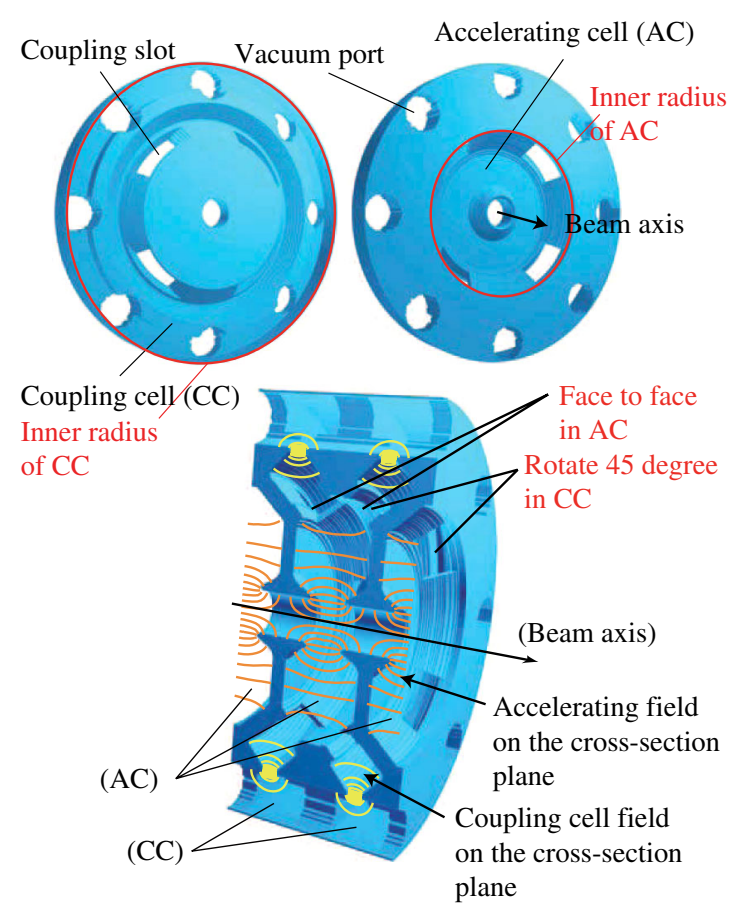

FIG. 1. Exploded view of the annular-ring coupled structure (ACS) for use in the J-PARC linac. The four coupling slots connect the accelerating-cell (AC) and the annular-ring-type coupling cell (CC). The slots are positioned face to face in the $\mathrm{AC}$ and then rotated 45 degrees in the $\mathrm{CC}$. The eight vacuum ports connect the adjacent $\mathrm{CC}$ for use in evacuating the entire cavity. The inner radii of the $\mathrm{AC}$ and $\mathrm{CC}$ are machined for precise frequency tuning. The field distributions were calculated by using SUPERFISH [6] for the axially symmetric cells (without the coupling slots). The beam does not see direct fields when the $\mathrm{CCs}$ are excited (even if there are the coupling slots). present cavity is discussed. (ii) The rf properties have to be measured at a low-power level in order to compare the measurement results with the design values. If there are frequency tuning errors, these errors adversely affect the on-axis electric-field amplitude. The electric-field distributions of the present cavity were measured for various positions of the adjustable plungers. The results could be explained using the coupled resonator model calculation. (iii) High-power conditioning is essential for evaluating the performance of the cavity. Typical issues include determining whether the conditioning time is acceptable and whether the vacuum pressure is sufficiently low. When we assume that frequency tuning errors (the accelerating- and coupling-cell frequency errors and the $\pi / 2$ mode frequency is tuned to the operating frequency using the adjustable plungers) excite the coupling cells, the frequency tuning error determines the maximum excited power of the coupling cell. The present (full-fledged) cavity increases the number of excited power levels among the coupling cells, in contrast to the short cavity. Thus, it increases the possibility that a coupling cell could be excited at near the field level of the multipactor. In order to find the issue caused by the excited coupling cells, the cavity was additionally conditioned at the higher and lower frequencies that were detuned from the operating frequency of $972 \mathrm{MHz}$. This procedure was comparable to conditioning with the coupling cells excited at a certain power level.

The remainder of the current report is divided as follows. First, Sec. II presents the configuration of the present (full-fledged) cavity, and Sec. III discusses the frequency shift due to brazing of the prototype modules. Next, Sec. IV details the measured frequencies and the frequency tuning processes, Sec. V summarizes the frequency shift due to brazing of this cavity, and Sec. VI examines the electric-field distribution with a low-level rf measurement. The highpower test results are shown in Sec. VII. Finally, in Sec. VIII we discuss the most reasonable scenario for frequency tuning and summarize the present results obtained from the first ACS cavity. 


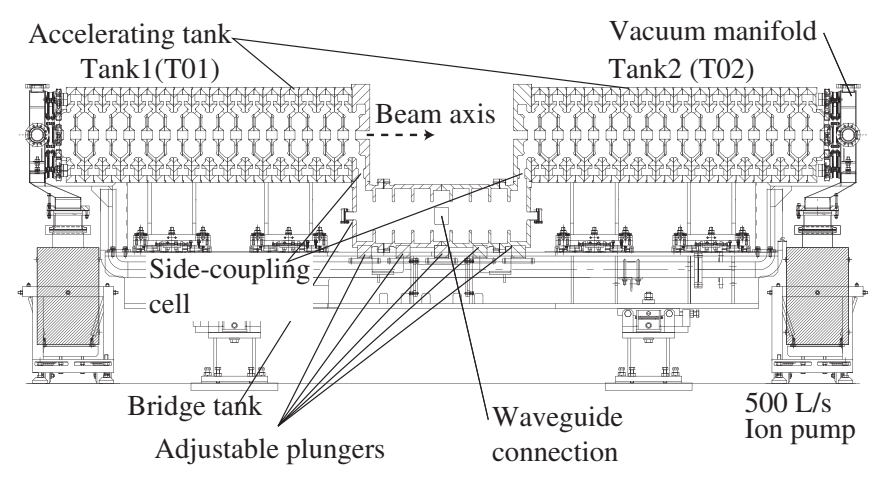

FIG. 2. Configuration of the ACS accelerating module (M01). One ACS "module" consists of two accelerating tanks (T01 and T02) and one bridge tank. The accelerating tank contains 17 accelerating and 16 coupling cells. The accelerating and bridge tanks are connected by a side-coupling cell located between these tanks. The accelerating-mode frequency can be tuned by the five adjustable tuning plungers. The bridge tank contains five accelerating-cell equivalents and four coupling-cell equivalents. The design of the bridge tank is detailed in Appendix A.

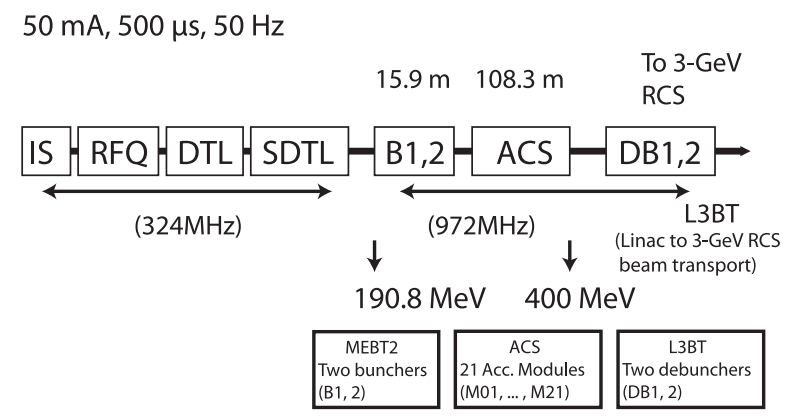

FIG. 3. Diagram of J-PARC linac accelerating structures. $\mathrm{H}^{-}$ beams are accelerated from 190.8 to $400 \mathrm{MeV}$ using the 21 ACS accelerating modules, two ACS bunchers $(\mathrm{B} 1,2)$, and two ACS debunchers (DB1,2). This configuration (the number of accelerating cells, coupling cells, and required modules) is detailed in [8].

\section{CONFIGURATION OF THE ACS ACCELERATING MODULE}

The present cavity is referred to as an accelerating module (M01). Figure 2 shows the configuration of the ACS accelerating module.

TABLE II. Main parameters for M01.

\begin{tabular}{lc}
\hline \hline Frequency & $972 \mathrm{MHz}$ \\
Geometric beta $(\beta)$ of tank 1 & $0.5583^{\mathrm{a}}$ \\
Geometric beta $(\beta)$ of tank 2 & $0.5631^{\mathrm{a}}$ \\
Accelerating field $E_{0}$ & $4.2 \mathrm{MV} / \mathrm{m}$ \\
Accelerating tank length of tank 1 & $1.464 \mathrm{~m}$ \\
Accelerating tank length of tank 2 & $1.476 \mathrm{~m}$ \\
Repetition & $50 \mathrm{~Hz}$ \\
Pulse length & $600 \mu \mathrm{s}$ \\
\hline \hline
\end{tabular}

${ }^{\mathrm{a}}$ Geometric beta (accelerating gap length) is constant in one accelerating tank.

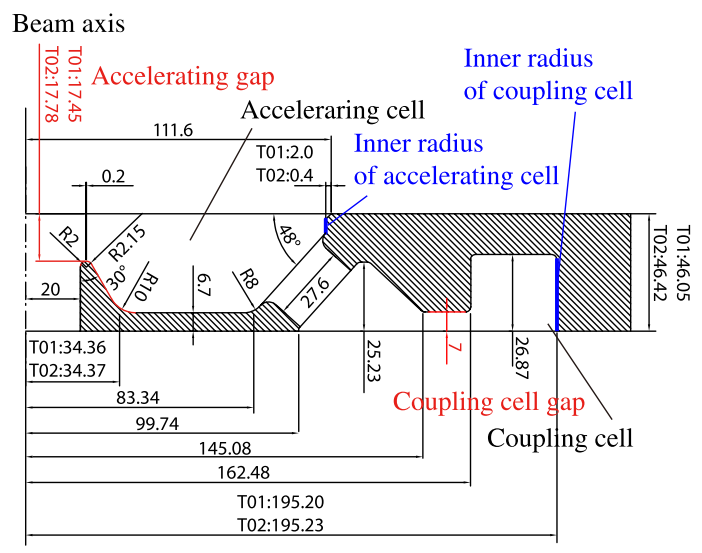

FIG. 4. Cell geometry of the ACS accelerating tank T01 and T02 (unit: mm).

Figure 3 shows a diagram of the J-PARC linac. $\mathrm{H}^{-}$beams are accelerated from 190.8 to $400 \mathrm{MeV}$ using the 21 ACS accelerating modules. The accelerating modules are numbered from M01 to M21, and the accelerating tanks are also numbered from T01 to T42, in order of increasing beam energy.

In this report, module 1 (M01) was fabricated and tested as the first full-fledged ACS cavity. The main parameters of M01 are listed in Table II. For all the accelerating modules, the cavity dimensions (bore radius, nose cone radius, and coupling slot geometry), except those involved in a geometric beta or frequency tuning, were designed using the same dimensions used for the buncher module in order to standardize and simplify the machining for the future mass production (see Fig. 4). The optimization of the cavity dimensions of the J-PARC ACS is detailed in [9].

\section{DESIGNED FREQUENCY BEFORE BRAZING}

The designed values of the accelerating- and couplingcell frequencies before brazing have to be determined while taking into account the thermal detuning during high-power operation and the frequency shift due to brazing. By using ANSYS [10], it was estimated that the accelerating-cell frequency would decrease by $0.04 \mathrm{MHz}$ during high-power operation, while the frequency change of the coupling cell would be negligible [11]. In addition, the estimated thermal detuning for the accelerating cell was in good agreement with the high-power test result obtained using buncher 1 [8]. Thus, these values were adopted also for M01.

The frequency shift due to brazing was evaluated using the measurement results of the prototype modules (bunchers 1 and 2). The frequency shifts due to brazing for bunchers 1 and 2 are listed in Table III.

For the accelerating-mode frequency, the maximum difference among the four tanks was $0.13-(-0.03)=$ $0.16 \mathrm{MHz}$, which is comparable to the required accuracy 
TABLE III. Frequency shift due to brazing (MHz).

\begin{tabular}{lcccc}
\hline \hline $\begin{array}{l}\text { Mccelerating mode) } \\
\text { Module }\end{array}$ & Tank number & Before & After & Shift \\
\hline Buncher 1 $^{\mathrm{a}}$ & 1 & $972.05^{\mathrm{b}}$ & 972.17 & +0.12 \\
& 2 & $972.03^{\mathrm{b}}$ & 972.16 & +0.13 \\
Buncher 2 & 1 & $971.73^{\mathrm{b}}$ & 971.74 & +0.01 \\
& 2 & $971.78^{\mathrm{b}}$ & 971.75 & -0.03 \\
\hline (Coupling mode) $^{\text {Module }}$ & Tank number & Before & After & Shift \\
\hline Buncher 1 & 1 & $971.36^{\mathrm{c}}$ & 971.46 & +0.10 \\
& 2 & $971.34^{\mathrm{c}}$ & 971.30 & -0.04 \\
Buncher 2 & 1 & $971.88^{\mathrm{c}}$ & 972.54 & +0.66 \\
& 2 & $971.77^{\mathrm{c}}$ & 972.45 & +0.68 \\
\hline \hline
\end{tabular}

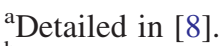

${ }^{\mathrm{b}}$ Average frequency among the five accelerating cells including the end-cell parts.

${ }^{c}$ Average frequency among the four coupling cells.

of $\pm 0.1 \mathrm{MHz}$. An expected frequency shift of $0 \mathrm{MHz}$ was, therefore, chosen for M01. This expected value was obtained by rounding the average frequency shift of buncher $2[(0.01-0.03) / 2=-0.01 \mathrm{MHz}]$ to $0 \mathrm{MHz}$.

For the coupling-mode frequency, the maximum difference among the four tanks was $0.68-(-0.04)=$ $0.72 \mathrm{MHz}$. The cause of this large difference is not well understood, partly because the deformation of the accelerating and coupling cells cannot be measured quantitatively after brazing. The scatter of these frequency shifts due to brazing is also discussed in Sec. V.

Because of this large difference, it is difficult to determine the expected frequency shift of the coupling mode. Here, we assume that the frequency shift due to brazing is caused by uniform deformation in the direction of the beam axis ( $z$ axis). The frequency sensitivities $d f / d z$ of the accelerating gaps and coupling-cell gaps are 0.014 and $0.033 \mathrm{MHz} / \mu \mathrm{m}$, respectively (see Fig. 4). Thus, the frequency shift of the coupling cell should be $0.033 / 0.014=$ 2.4 times as large as that of the accelerating cell. Using a maximum frequency shift of $0.13 \mathrm{MHz}$ (from tank 2 of buncher 1, see Table III) for the accelerating mode, the maximum frequency shift for the coupling mode can be estimated to be $0.13 \times 2.4=0.31 \mathrm{MHz}$. In contrast, the average frequency shift obtained from buncher 2 was $(0.66+0.68) / 2=0.67 \mathrm{MHz}$, which is twice as large as the above estimated value of $0.31 \mathrm{MHz}$. Considering these facts, we chose $0.1 \mathrm{MHz}$ as the expected frequency shift for M01, which is the measured value from tank 1 of buncher 1 .

Consequently, in order to obtain the operating frequency of $972 \mathrm{MHz}$ during high-power operation, the accelerating- and coupling-cell frequencies before brazing were designed as 972 (operating frequency) + 0.04 (thermal detuning) $=972.04 \mathrm{MHz}$ and $972-$ 0.1 (frequency shift) $=971.90 \mathrm{MHz}$, respectively.

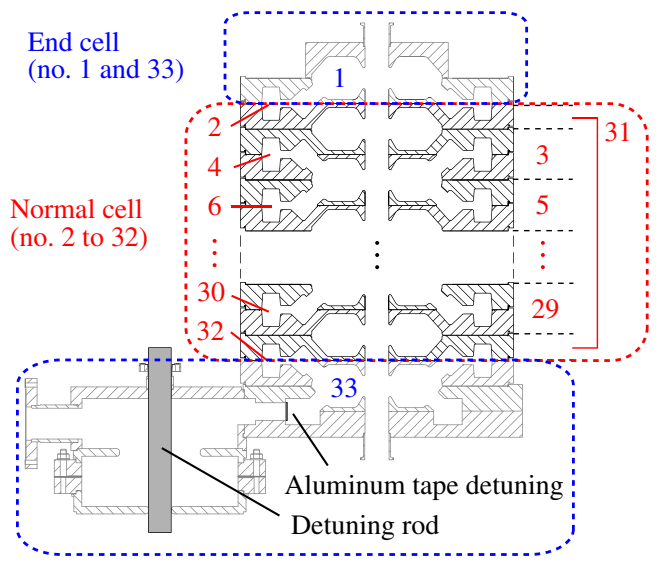

FIG. 5. Groupings for frequency tuning. The numbers from 1 to 33 show the identification numbers of the accelerating and coupling cells.

\section{FREQUENCY TUNING PROCESSES AND RESULTS BEFORE BRAZING}

The required accuracies of the accelerating- and coupling-cell frequencies for each cell are $\pm 0.1 \mathrm{MHz}$; this value was chosen so that the field flatness would remain smaller than $1 \%$ (detailed in [8]). For the coupling-cell frequency, an absolute deviation for each cell of $\pm 0.4 \mathrm{MHz}$ is tolerable for a field flatness of $1 \%$, as long as the average frequency is within the range of $\pm 0.1 \mathrm{MHz}$.

The cell frequencies were tuned separately in two groups: the normal cells and end cells (see Fig. 5). Since the normal cells have a biperiodic structure, the cell frequency can be measured by realizing the original boundary condition electromagnetically with shorting plates. On the other hand, the tuning procedure of the end cell is detailed in Appendix B. Table IV lists the end-cell frequencies after frequency tuning. It can be seen from Table IV that the endcell frequencies could be tuned approximately within the required accuracy of $\pm 0.1 \mathrm{MHz}$.

Figure 6(a) shows the accelerating-cell frequencies for T01 before frequency tuning. The average frequency was $973.52 \pm 0.15 \mathrm{MHz}$, which was $0.24 \mathrm{MHz}$ higher than the target frequency of $973.28 \mathrm{MHz}$. This target frequency was determined by adding a frequency tuning margin of $1.36 \mathrm{MHz}$, which is equivalent to increasing the inner radius of the accelerating cell by $1.1 \mathrm{~mm}$ (the maximum tuning length is $2 \mathrm{~mm}$, see Fig. 4), to the final target frequency of $971.92 \mathrm{MHz}$ [see Fig. 6(b)]. Here, the

TABLE IV. End-cell frequencies after frequency tuning vs designed frequency $(\mathrm{MHz})$.

\begin{tabular}{lccc}
\hline \hline Cell number & Designed & Measured & Difference \\
\hline (T01) 1 and 33 & 972.04 & 971.93 & -0.11 \\
(T02) 1 and 33 & 972.04 & 972.09 & +0.05 \\
\hline \hline
\end{tabular}


(a) Before frequency tuning

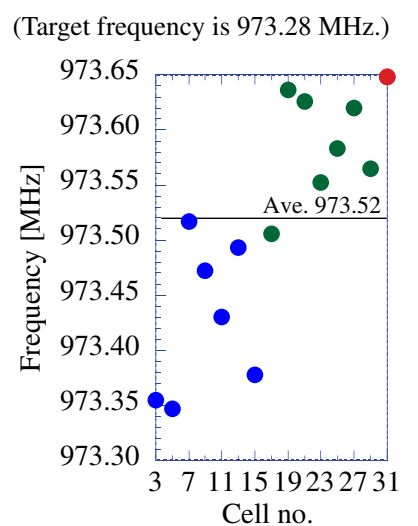

Target frequency $971.92 \pm 0.1 \mathrm{MHz}$

(c) After 1st tuning

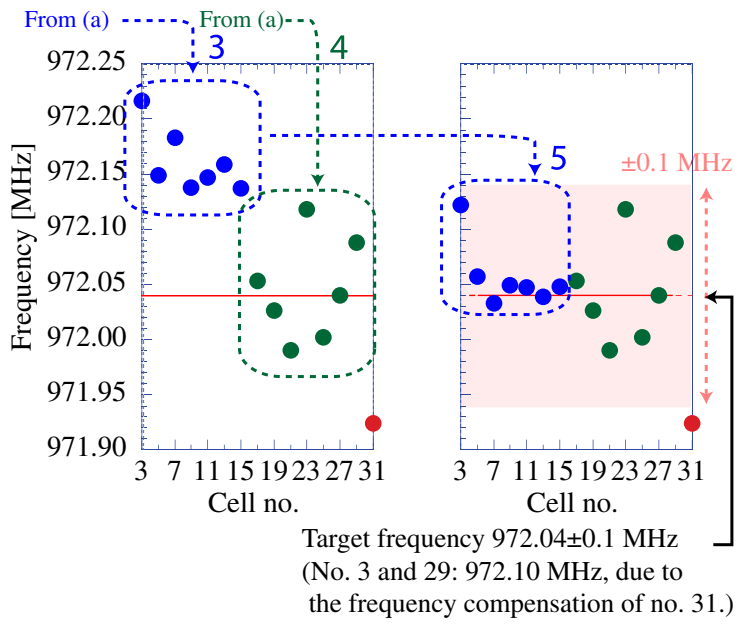

FIG. 6. Frequency tuning procedure for T01 accelerating cell. The numbers from 1 to 5 show the order of the frequency tuning. The average frequency (ave.) is also presented. In part (b), the target frequency of $971.92 \mathrm{MHz}$ was determined by 972 (operating frequency) +0.04 (thermal detuning) -0.12 (frequency shift due to brazing). Here, the frequency shift was expected to be $0.12 \mathrm{MHz}$ obtained from only the result of buncher 1 (see Table III). In contrast, in parts (c) and (d), the target frequency was modified to $972.04 \mathrm{MHz}$ as described in Sec. III, since it was found that the frequency shift of buncher 2 was only $-0.01 \mathrm{MHz}$ on average (see Table III) after the frequency tuning of number 31.

uncertainty is half of the difference between the maximum and the minimum values. Unless otherwise specified, the uncertainties of measured frequencies are as defined above.

Since all the accelerating cells for T01 were machined using the same dimensions, the frequency uncertainty of $\pm 0.15 \mathrm{MHz}$ can be interpreted as being due to a machining error. This deviation of $\pm 0.15 \mathrm{MHz}$ did not meet the required accuracy of $\pm 0.10 \mathrm{MHz}$. This result indicates that at least one round of frequency tuning is required for tuning the accelerating-cell frequencies.
Figure 6(b) shows the tuning process of cell number 31. The frequency of cell number 31 was tuned first in order to obtain the value of $d f / d r$, where $f$ and $r$ are the resonant frequency and inner radius of the accelerating cell, respectively (see Figs. 1 and 4). In the tuning process, the inner radius $r$ of the accelerating cell was machined and increased in order to decrease the frequency. The coefficient $d f / d r$ was determined by the measured frequency decrease $\Delta f$ and the increased radius $\Delta r$. The absolute values of $\Delta f, \Delta r$, and $d f / d r$ in steps 1 and 2 are listed in Table V. These two coefficients are consistent within measurement error.

As shown in Fig. 6(c), cells number 3 to 15 were tuned in step 3, where the frequency was aimed at $972.04 \mathrm{MHz}$ using a coefficient of $1.27 \mathrm{MHz} / \mathrm{mm}$. This coefficient was slightly larger than $1.24 \mathrm{MHz} / \mathrm{mm}$ (see Table V) in order to avoid reducing the frequency too much. A new value of $d f / d r$ of $1.17 \pm 0.02 \mathrm{MHz}$ was obtained using the results of step 3. Then, in step 4, cells number 17 to 29 were tuned using the new coefficient of $1.17 \mathrm{MHz} / \mathrm{mm}$.

The difference in the value of $d f / d r$ between 1.17 and $1.24 \mathrm{MHz} / \mathrm{mm}$ (measured in step 1) is significantly larger than the expected accuracy of $\pm 0.02 \mathrm{MHz} / \mathrm{mm}$ (see Table V). The reason for this difference is not well understood. However, this result indicates that we should take care in using the value of $d f / d r$, especially when it is evaluated using the result for only one cell.

As shown in Fig. 6(d), cells number 3 to 15 were corrected again in step 5. It can be seen that the deviation of cells number 5 to $15( \pm 0.02 \mathrm{MHz})$ was smaller than that of cells number 17 to $27( \pm 0.07 \mathrm{MHz})$, since the tuning length $d r$ of the former $(0.093 \mathrm{~mm}$ on average) was smaller than that of the latter (1.322 $\mathrm{mm}$ on average). This result clearly shows that reducing $d r$ is effective for minimizing the tuning error.

Figure 7(a) shows the accelerating-cell frequencies for T02 before frequency tuning. The frequencies of cells number 3 and 31 were far from the average value because they were mismachined at the accelerating gaps by 0.06 and $0.14 \mathrm{~mm}$. These two cells were tuned separately. As shown in Fig. 7(b), cells number 5 to 29 could be tuned within a deviation of $\pm 0.06 \mathrm{MHz}$.

TABLE V. Coefficient $d f / d r(\mathrm{MHz} / \mathrm{mm})$ of T01 measured in frequency tuning steps 1 and 2 [see. Fig. 6(b)].

\begin{tabular}{lcccc}
\hline \hline Tuning step & $\Delta f(\mathrm{MHz})$ & $\Delta r(\mathrm{~mm})$ & $d f / d r$ & Used $d f / d r$ \\
\hline 1 & 1.580 & 1.279 & $1.24 \pm 0.02^{\mathrm{a}}$ & $1.21^{\mathrm{b}}$ \\
2 & 0.144 & 0.100 & $1.44 \pm 0.33^{\mathrm{c}}$ & $1.24^{\mathrm{d}}$ \\
\hline \hline
\end{tabular}

${ }^{\mathrm{a}}$ Given by $0.03 / 1.279$, since the accuracy of the frequency measurement is $\pm 0.03 \mathrm{MHz}$. The contribution of a machining error of $\pm 0.01 \mathrm{~mm}$ is negligibly small.

${ }^{\mathrm{b}}$ Evaluated by using SUPERFISH.

${ }^{\mathrm{c}}$ Given by $\sqrt{(0.03 / 0.1)^{2}+(0.144 / 0.1)^{2} \times(0.01 / 0.1)^{2}}$ using propagation of error, where the accuracy of the frequency measurement and the machining error are $\pm 0.03 \mathrm{MHz}$ and $\pm 0.01 \mathrm{~mm}$, respectively.

${ }^{\mathrm{d}}$ Obtained from step 1 . 
(a) Before frequency tuning

(b) After 1st tuning

(Target frequency is $972.11 \mathrm{MHz}$.)
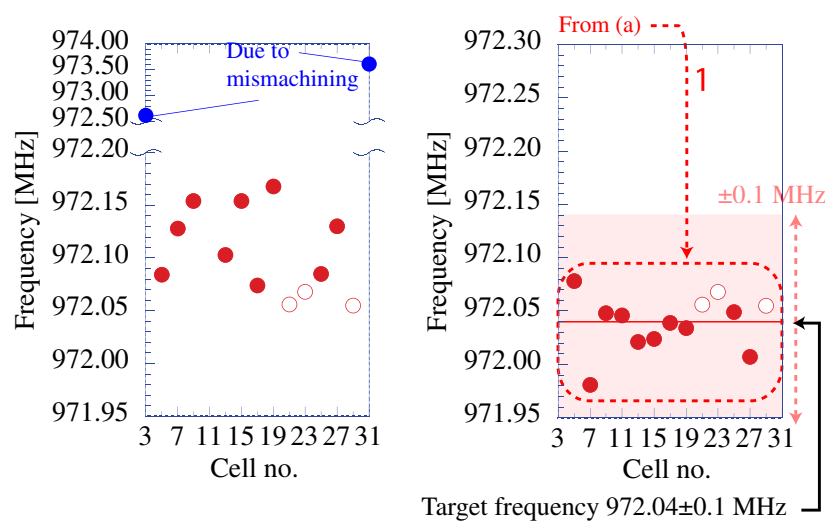

FIG. 7. Frequency tuning procedure for T02 accelerating cell. The initial dimensions of T02 were designed using its own prototype. Thus, the target frequency before frequency tuning of $972.11 \mathrm{MHz}$ was much closer to the designed value of $972.04 \mathrm{MHz}$ than that of T01 [see Fig. 6(a)]. The number 1 shows the order of the frequency tuning. The frequency tuning for cells number 21, 23, and 29 (open circles) was skipped.

Figure 8 shows the coupling-cell frequencies for T01 and T02. As shown in Fig. 8, the coupling-cell frequencies for T01 and T02 before frequency tuning were aimed at the designed value of $971.9 \mathrm{MHz}$ directly in order to reduce the work involved in frequency tuning, and the resulting average frequencies for T01 and T02 were 972.04 \pm 0.26

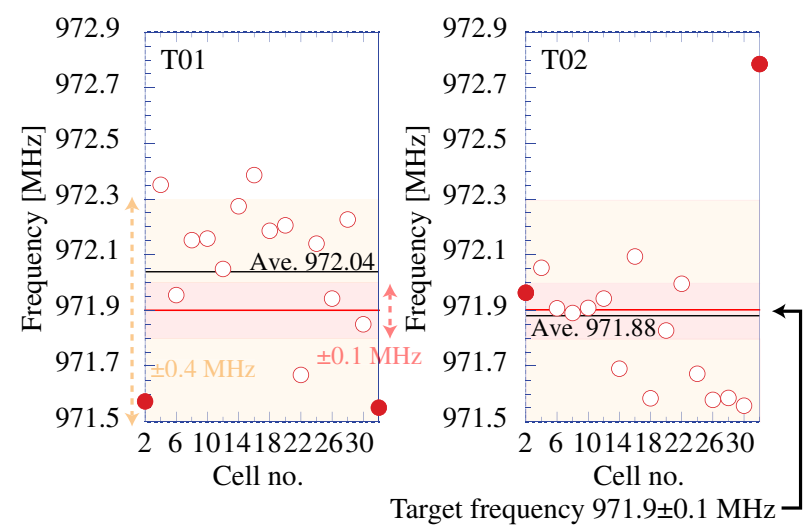

FIG. 8. Coupling-cell frequencies for T01 and T02 after the frequency tuning of cells number 2 and 32 . The frequency tuning for the other cells (open circles) could be skipped. The same dimensions of the coupling cell (see Fig. 4) were used for those of cells number 2 and 32. In this case, the frequency of cells number 2 and 32 becomes higher than that of other coupling cells due to the difference of a boundary condition for the vacuum ports (see Fig. 1), since these cells are positioned at both ends of the accelerating tank (see Fig. 5). Thus, the frequency was decreased by machining and increasing the inner radius of these coupling cells (see Figs. 1 and 4). The average frequencies (ave.) for T01 and T02 are also presented. The absolute deviation for each cell of $\pm 0.4 \mathrm{MHz}$ is tolerable, as long as the average frequency is within the range of $\pm 0.1 \mathrm{MHz}$.
(SD) $\mathrm{MHz}$ and $971.88 \pm 0.30(\mathrm{SD}) \mathrm{MHz}$, respectively [the frequency uncertainties are standard deviations (SD)]. The absolute deviations of the frequency were lower than $0.4 \mathrm{MHz}$, except in three cells (numbers 4 and 16 for T01 and number 32 for T02). Further frequency tuning of these three cells was skipped, since the field flatness was evaluated to be $0.08 \%$ by using all the measured frequencies and the expected frequency shifts due to brazing with a coupled resonator model [3]. In regard to the average frequency, although that of T01 was higher than the required value of $971.9 \pm 0.1 \mathrm{MHz}$ by $0.04 \mathrm{MHz}$, we tolerated it on the basis of the evaluation of the coupled resonator model.

Although the average coupling-cell frequencies barely met the required accuracy of $971.9 \pm 0.1 \mathrm{MHz}$, these results show that the standard deviations of the coupling-cell frequency were 3 times as large as the required accuracy of $\pm 0.1 \mathrm{MHz}$. Thus, this result indicates that at least one round of the tuning process is also required for the coupling-cell frequencies.

\section{FREQUENCY SHIFT DUE TO BRAZING}

Figures 9 and 10 show the variations of the cell frequencies due to the brazing processes. First, the part connecting the accelerating tank and the bridge tank was brazed [the brazed parts are surrounded with the dotted red lines in Figs. 9(b) and 10(b)]. Figures 9(b) and 10(b) show that the frequencies of the end-cell parts (average frequencies of cells number 1 and 33) for T01 and T02 varied by +0.14 and $-0.21 \mathrm{MHz}$, respectively, during the first brazing.

As a next step, Figs. 9(c) and 10(c) show the frequencies for T01 and T02 after the final brazing. The acceleratingmode frequency $f_{a}$ is the $\pi / 2$ mode frequency, while the coupling-mode frequency $f_{c}$ was evaluated from the following equation:

$$
f_{c}=f_{u}+f_{l}-f_{a},
$$

where $f_{u}$ is the nearest higher mode to the $\pi / 2$ mode and $f_{l}$ is the nearest lower mode to the $\pi / 2$ mode [12].

Table VI lists the frequency shifts due to brazing. It can be seen that the frequency shift of the accelerating mode was $+0.16 \mathrm{MHz}$ on average, which is larger than the expected shift of $0 \mathrm{MHz}$. In contrast, the frequency shift of the coupling mode was $+0.67 \mathrm{MHz}$ on average, which is considerably larger than the expected shift of $+0.10 \mathrm{MHz}$. Although there were differences between the measured value and the expected frequency shift, no significant difference due to the number of cells was observed in the frequency shifts between the prototype module and the accelerating module.

At this point, it can be seen from Tables III and VI that the frequency shifts of the accelerating mode are distributed from -0.03 to $+0.17 \mathrm{MHz}$ and the average is $+0.09 \pm 0.1 \mathrm{MHz}$, where the uncertainty is half of the difference between the maximum and minimum values. 

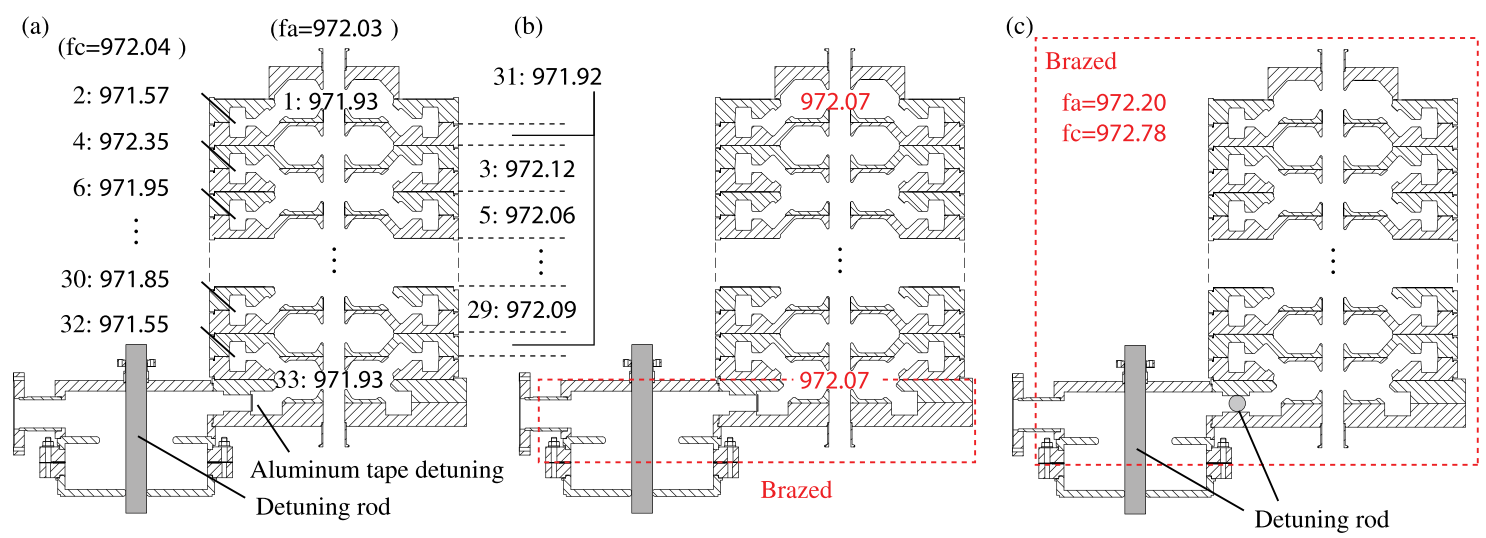

FIG. 9. Variation of the cell frequencies of T01 due to the brazing processes. The bridge tank and the coupling cell between the accelerating tank and the bridge tank were detuned with a detuning rod or aluminum tape with a width of $4 \mathrm{~mm}$. The dotted red lines surround the brazed parts. In contrast to the procedure used for buncher 1, here the end-cell part that connects the accelerating and bridge tank was positioned facing downward in the brazing furnace for mechanical stability at high temperatures. (a) After frequency tuning. The accelerating-mode $(f a)$ and coupling-mode frequencies $(f c)$ were evaluated by averaging the accelerating- and couplingcell frequencies. (b) After the first brazing. (c) Accelerating-mode and coupling-mode frequencies after the final brazing.
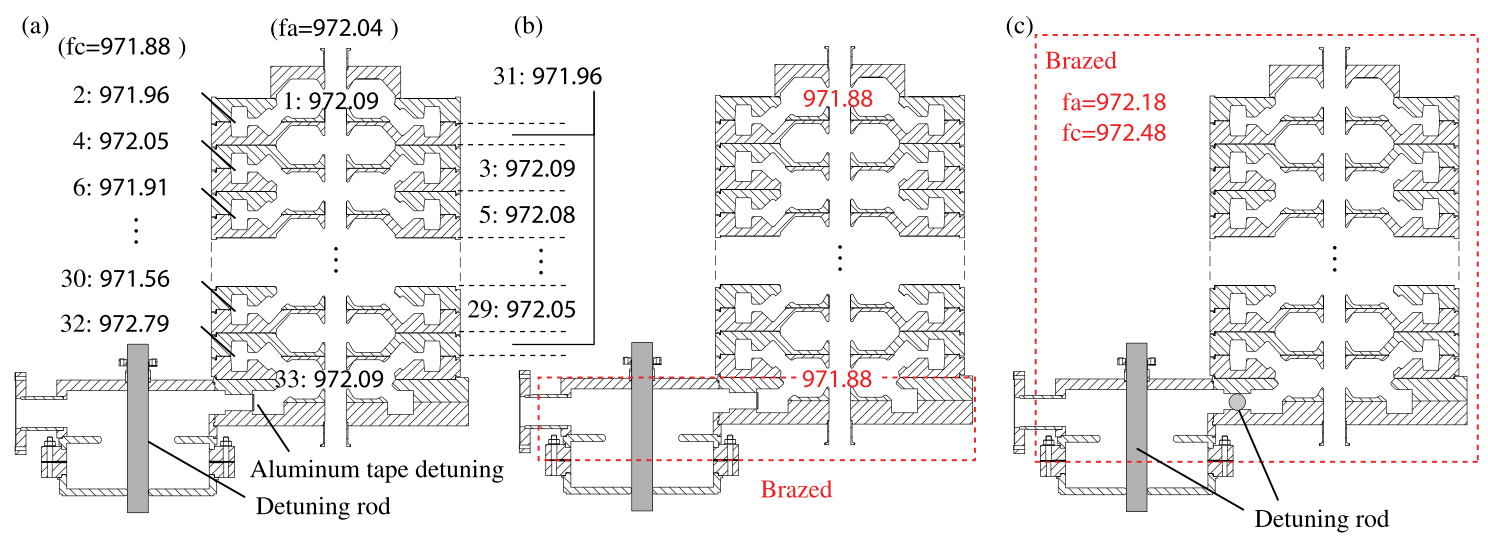

FIG. 10. Variation of the cell frequencies of T02 due to the brazing processes.

TABLE VI. Accelerating tank frequencies after the final brazing and frequency shifts due to brazing $(\mathrm{MHz})$.

\begin{tabular}{|c|c|c|c|c|}
\hline \multicolumn{5}{|c|}{ (Accelerating mode) } \\
\hline Tank & Before & After & Shift & Expected \\
\hline T01 & $972.03^{\mathrm{a}}$ & 972.20 & +0.17 & \\
\hline T02 & $972.04^{\mathrm{a}}$ & 972.18 & +0.14 & \\
\hline Average & & & +0.16 & $+0.0^{\mathrm{b}}$ \\
\hline \multicolumn{5}{|c|}{ (Coupling mode) } \\
\hline Tank & Before & After & Shift & Expected \\
\hline T01 & $972.04^{\mathrm{c}}$ & 972.78 & +0.74 & \\
\hline T02 & $971.88^{\mathrm{c}}$ & 972.48 & +0.60 & \\
\hline Average & & & +0.67 & $+0.10^{\mathrm{b}}$ \\
\hline
\end{tabular}

${ }^{a}$ Average frequency among the 17 accelerating cells including the end-cell parts [see Figs. 9(a) and 10(a)].

${ }^{\mathrm{b}}$ Expected frequency shifts were determined from the brazing results of the prototype modules (detailed in Sec. III).

${ }^{\mathrm{c}}$ Average frequency among the 16 coupling cells [see Figs. 9(a) and $10(\mathrm{a})]$.
This uncertainty still satisfies the required accuracy of $\pm 0.1 \mathrm{MHz}$. Thus, the frequency shifts of the accelerating mode do not seem to be critical.

In contrast, the frequency shifts of the coupling mode were scattered from -0.04 to $+0.74 \mathrm{MHz}$ and the average is $+0.46 \pm 0.39 \mathrm{MHz}$. This uncertainty is significantly larger than the required accuracy of $\pm 0.1 \mathrm{MHz}$. However, the results for the last two modules (buncher 2 and M01) were $0.67 \pm 0.07 \mathrm{MHz}$. If this trend continues, the predicted value of the frequency shift due to brazing, therefore, will be further improved by using experimental data of cavities that will be fabricated in the near future. In this case, the frequency shifts of buncher 1 may have included a systematic error.

The frequency uncertainties of the frequency tuning and the brazing are listed in Table VII. The field flatness is evaluated to be $5.0 \%$ by using the maximum uncertainties (in Table VII) and the coupled resonator model. This field flatness, a field flatness of several percent, is assumed to be 
TABLE VII. Frequency uncertainties of the frequency tuning and the brazing $(\mathrm{MHz})$.

\begin{tabular}{lccc}
\hline \hline Mode & Frequency tuning & Brazing & Maximum $^{\mathrm{a}}$ \\
\hline Accelerating & $\pm 0.08^{\mathrm{b}}$ & \pm 0.1 & \pm 0.18 \\
Coupling & $\pm 0.08^{\mathrm{c}}$ & \pm 0.39 & \pm 0.47 \\
\hline \hline
\end{tabular}

${ }^{a}$ Sum of the uncertainties of the frequency tuning and the brazing.

${ }^{b}$ Half of the difference between the maximum and minimum values in Figs. 6(d) and 7(b) except cell number 31 of T01.

${ }^{c}$ Half of the difference between the maximum and minimum values of the average frequencies in Fig. 8.

acceptable on the basis of preliminary IMPACT simulations $[13,14]$. However, the degradation of the field flatness due to the frequency tuning error should be minimized as small as possible to maximize the advantage of the ACS that the dipole component in the accelerating field is negligible small. If the uncertainty of the brazing for the coupling mode decreases to $0.07 \mathrm{MHz}$ (uncertainty of the last two modules), the field flatness is improved to $1.6 \%$. In this regard, the tuning of the coupling-mode frequency, especially for the frequency shift due to brazing, is still a key issue in the fabrication of the ACS.

\section{LOW-LEVEL RF MEASUREMENT}

After assembling a complete accelerating module, the electric-field distribution of M01 along the beam axis $(z$ axis) was measured using the bead-pull method. The frequency perturbation was evaluated from the phase shift at the unperturbed resonant frequency. The bead was pulled by a pulsed motor at a constant speed, and a vector network analyzer measured the phase shift continuously.

Figure 11 shows typical electric-field distributions for various positions of the adjustable plungers: (a) at the outer limit (971.70 MHz), (b) for tuning to the operating frequency of $972 \mathrm{MHz}$, and (c) at the inner limit (972.39 MHz). In addition, Fig. 11 also shows the electric-field amplitude calculated with the coupled resonator model using the measured frequencies for T01 and T02 [see Figs. 9(c) and 10(c)]. Here, the units of the vertical axes are arbitrary. However, the normalizing factors of these three plots, including the coupled resonator model calculations, were the same. Thus, we can compare the correlations between the electric-field distribution and the position of the adjustable plungers in these three plots quantitatively. It can be seen that the electric-field amplitudes were well explained using the coupled resonator model calculation. Thus, the accelerating-mode and coupling-mode frequencies that were higher than $972 \mathrm{MHz}$ resulted in a nonuniform distribution of the on-axis electric-field amplitude at $972 \mathrm{MHz}$, as shown in Fig. 11(b).

The measured $Q$ and $R / Q$ values at $972.00 \mathrm{MHz}$ were smaller than those at $972.39 \mathrm{MHz}$ because of the nonuniform electric field. Table VIII, therefore, compares
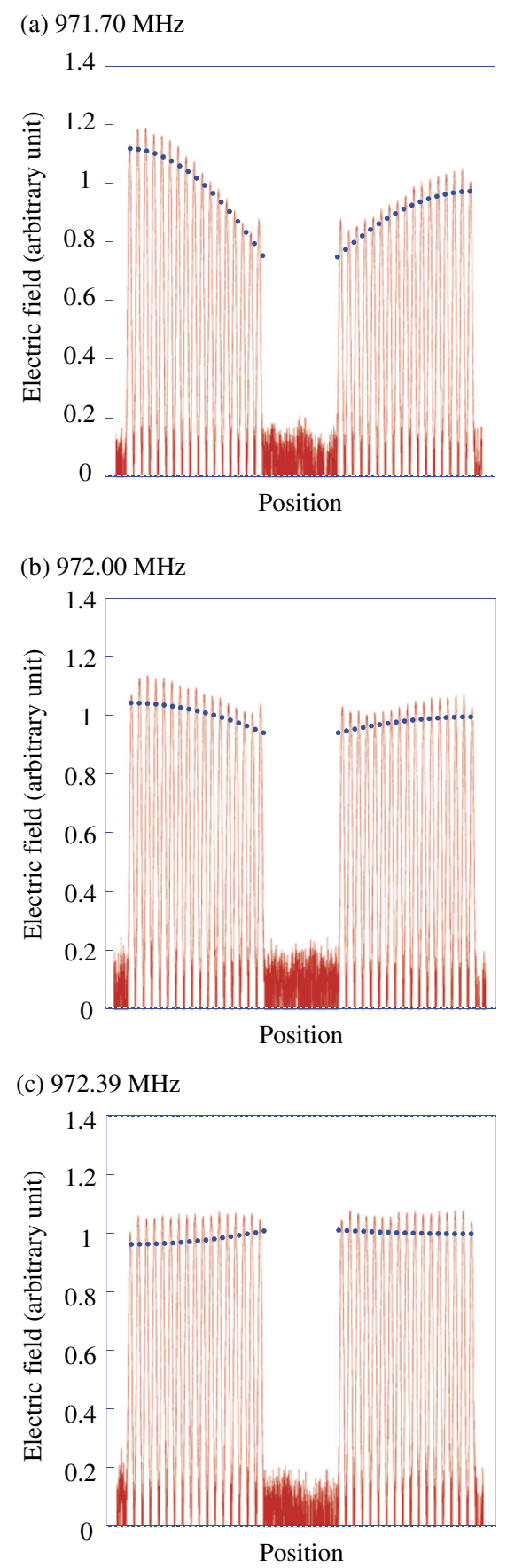

FIG. 11. Typical electric-field distributions of M01 for various plunger positions: (a) outer limit, (b) tuning to the operating frequency of $972 \mathrm{MHz}$, and (c) inner limit. The red lines show the electric fields measured with the bead-pull method. The blue solid circles indicate the electric-field amplitude calculated with the coupled resonator model using the measured frequencies for T01 and T02 [see Figs. 9(c) and 10(c)].

the calculated and measured values of the cavity's $Q$ and $R / Q$ values at $972.39 \mathrm{MHz}$. This module achieved $95.8 \pm$ $6.7 \%$ of the calculated value of $R / Q$. This result indicates that there was no significant degradation of $Q$ and $R / Q$ in the fabrication process. 


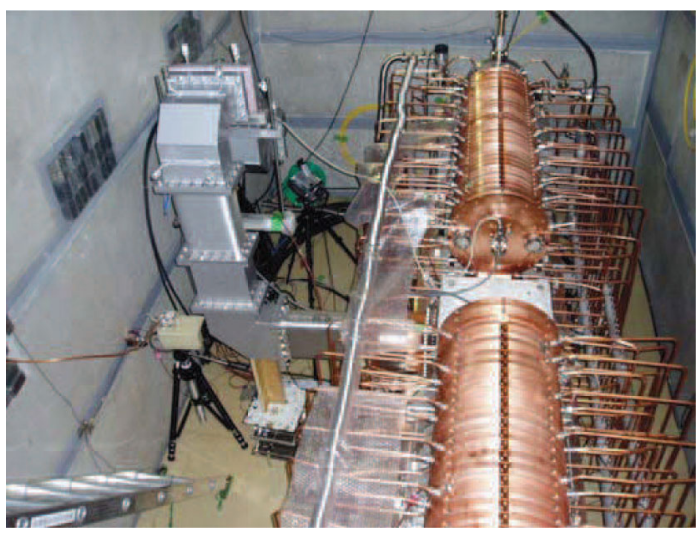

FIG. 12. First ACS accelerating module (M01) installed in the high-power test area.

\section{HIGH-POWER TEST}

\section{A. Measurement setup}

After the low-level measurement, M01 was installed in the high-power test area for its conditioning (see Fig. 12). The system for monitoring the cavity performance is shown in Fig. 13. In this system, the input power $\left(P_{\text {in }}\right)$, reflection power $\left(P_{r}\right)$, and electric fields of each end cell $\left(E_{\text {cav }}\right)$ are monitored. The four fields were measured to find the imbalance between the two accelerating tanks. The power dissipation of the cavity was evaluated independently using the flow and temperature rise in the cooling water.

The two $500 \mathrm{~L} / \mathrm{s}$ ion pumps equipped at both ends of the accelerating tank evacuated the whole module (see Fig. 2). The vacuum pressure at the center of the bridge tank was measured with a Bayard-Alpert gauge. The rf power was shut off at a certain value of the reflected power in order to prevent damage to the cavity and rf window. The rf power was also turned off at a vacuum pressure of $1 \times 10^{-4} \mathrm{~Pa}$.

\section{B. Conditioning history}

In order to generate the designed accelerating field of 4.2 MV/m, a cavity dissipation power of $1.3 \mathrm{MW}$ is required, since the measured shunt impedance is $39.6 \mathrm{M} \Omega / \mathrm{m}$ at $972 \mathrm{MHz}$ with a cavity length of $2.94 \mathrm{~m}$. Thus, the maximum power dissipation of 1.6 MW was determined by including a margin of $20 \%$ for the power.

TABLE VIII. Cavity's $Q$ and $R / Q$ values.

\begin{tabular}{lccc}
\hline \hline & Calculated $^{\mathrm{a}}$ & Measured & $\%$ \\
\hline$Q$ value & 18148 & 17611 & 97.0 \\
$R / Q$ & $6.97 \times 10^{3} \Omega$ & $6.68 \pm 0.47 \times 10^{3} \Omega^{\mathrm{b}}$ & $95.8 \pm 6.7^{\mathrm{b}}$ \\
\hline \hline
\end{tabular}

The calculation is detailed in Appendix C.

${ }^{\mathrm{b}}$ This error was evaluated by shifting the zero axis by $\sigma=$ $\pm 0.018 \mathrm{kHz}$, which was the typical standard deviation of the measured frequency shift when the bead was positioned outside of the cavity, for the electric-field (square root of the frequency shift) integration.

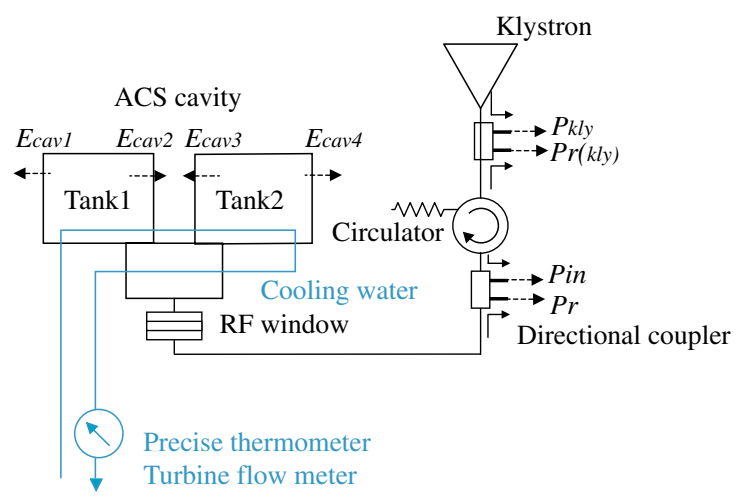

FIG. 13. Schematic view of the system for monitoring the cavity performance.

Figure 14 shows the conditioning history of M01. At the beginning of the conditioning, the peak power was increased at a repetition rate of $50 \mathrm{~Hz}$ (the same as the designed value) with a fixed short pulse length of $20 \mu \mathrm{s}$ (the designed value is $600 \mu \mathrm{s}$ ). The operating frequency of $972.15 \mathrm{MHz}$ was selected in order to condition the cavity with the uniform distribution of the on-axis electric-field amplitude. The output frequency of the klystron was also shifted to $972.15 \mathrm{MHz}$. It took 25 hours to reach the peak power of 1.6 MW with the short pulse. After that, the pulse length was extended from 20 up to $600 \mu \mathrm{s}$. The target input power (a peak power of $1.6 \mathrm{MW}$, a pulse length of $600 \mu \mathrm{s}$, and a repetition of $50 \mathrm{~Hz}$ ) was reached after 45 hours. Table IX compares this conditioning time with that of buncher 1, which is a short cavity comprising 10 accelerating cells in total.

There are 3.4 times more accelerating cells in M01 than in the buncher module. By comparison, the conditioning time required for M01 was 1.5 times longer than that required for buncher 1. (In this regard, the final accelerating field of 4.7 MV/m was $10 \%$ lower than that of buncher 1 ,

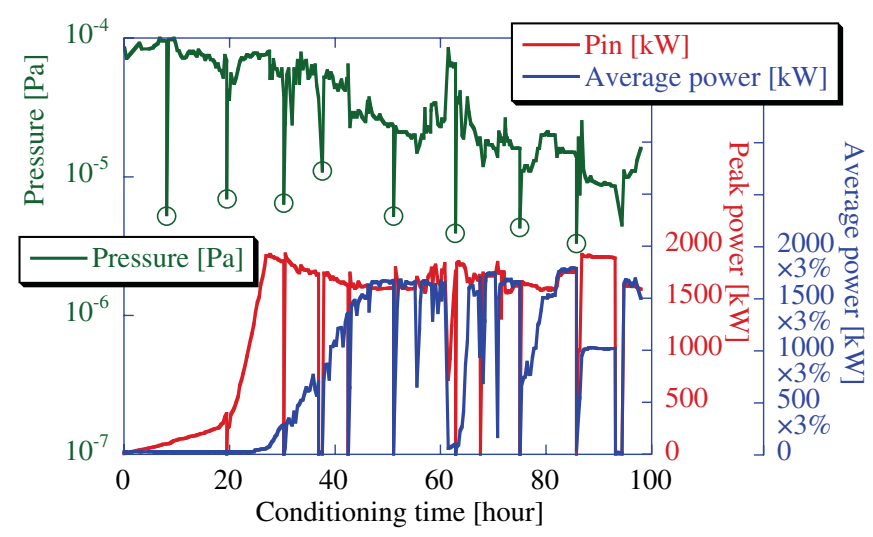

FIG. 14. Conditioning history of the first accelerating module (M01). Here $P_{\text {in }}$ is the input power, as shown in Fig. 13. This graph shows data points taken each 20 minutes. Thus, a short downtime does not appear in this graph. The pressure graph shows the pressure at the center of the bridge cavity. The green circles show the pressure without rf input. 
TABLE IX. Conditioning time and power levels for M01 and buncher 1 .

\begin{tabular}{lccccc}
\hline \hline & $\begin{array}{c}\text { Time } \\
(\mathrm{h})\end{array}$ & $\begin{array}{c}\text { Power } \\
(\mathrm{kW})\end{array}$ & $\begin{array}{c}E_{0}{ }^{\mathrm{a}} \\
(\mathrm{MV} / \mathrm{m})\end{array}$ & $\begin{array}{c}E_{s p}{ }^{\mathrm{b}} \\
(\mathrm{MV} / \mathrm{m})\end{array}$ & $E_{s p} / E_{k}{ }^{\mathrm{c}}$ \\
\hline Buncher 1 $^{\mathrm{d}}$ & 33 & 600 & 5.3 & 29.6 & 1.0 \\
M01 & 45 & 1600 & 4.7 & 26.2 & 0.9 \\
\hline \hline
\end{tabular}

${ }^{\mathrm{a}}$ Accelerating field.

${ }^{\mathrm{b}}$ Maximum surface field.

${ }^{\mathrm{c}}$ Kilpatrick field $E_{k}=28.3 \mathrm{MV} / \mathrm{m}$ for $972 \mathrm{MHz}$.

${ }^{\mathrm{d}}$ Ten accelerating cells and $0.9 \mathrm{~m}$ long.

${ }^{\mathrm{e}}$ Thirty-four accelerating cells and $2.9 \mathrm{~m}$ long.

5.3 MV/m.) Practically speaking, this time requirement is acceptable if mass produced modules are to be conditioned in the future.

After the initial conditioning at $972.15 \mathrm{MHz}$, this cavity was also conditioned up to $1.6 \mathrm{MW}$ at the frequencies that occurred when its adjustable plungers were positioned at their inward $(+45 \mathrm{~mm})$ and outward $(-10 \mathrm{~mm})$ limits. No operating issues, especially those due to a multipactor effect, were observed during this conditioning. This result means that, even though the coupling cells were excited at a certain power level, this cavity could be operated stably.

The vacuum pressure required to reduce the beam loss from residual gas to less than $0.1 \mathrm{~W} / \mathrm{m}$ is $4 \times 10^{-6} \mathrm{~Pa}$. However, the pressure at the center of the bridge cavity was $1 \times 10^{-5} \mathrm{~Pa}$ with rf input power and $4 \times 10^{-6} \mathrm{~Pa}$ without rf input power. Thus, an additional ion pump equipped at the bridge tank is planned for future operation.

Next we consider the field flatness during high-power operation. Here, the flatness is defined by $\left(x_{\max }-x_{\min }\right) / \bar{x}$, where $x_{\max }, x_{\min }$, and $\bar{x}$ are the maximum, minimum, and average values of the electric-field amplitude (square root of the frequency shift), respectively. As shown in Fig. 11, the field flatness improves when the adjustable plungers are inserted. The field flatness at a plunger position of $23 \mathrm{~mm}$ is $12.2 \%$, which corresponds to a resonant frequency of $972 \mathrm{MHz}$ at a cavity temperature of $27^{\circ} \mathrm{C}$ without rf input power. During the high-power operation (a peak power of 1.6 MW, a pulse length of $600 \mu \mathrm{s}$, and a repetition of $50 \mathrm{~Hz}$ ), the plunger position for $972 \mathrm{MHz}$ changed to $32 \mathrm{~mm}$ as the cavity temperature progressively increased. In this operation, the cavity was cooled by cooling water $\left(27^{\circ} \mathrm{C}\right)$ at a flow rate of $100 \mathrm{~L} / \mathrm{min}$. With increasing the plunger position, the flatness improved to $2.9 \%$. The relationship between the flatness and the position of the adjustable plungers (by the low-level measurement) is

TABLE X. Flatness of the electric field by the low-level measurement.

\begin{tabular}{lccc}
\hline \hline $\begin{array}{l}\text { Plunger } \\
\text { position }\end{array}$ & \multicolumn{2}{c}{ Flatness of tank } & $\begin{array}{r}\text { Flatness of module } \\
\text { (T01 and T02) }\end{array}$ \\
\hline $23 \mathrm{~mm}$ & $11.4 \%$ & $6.0 \%$ & $12.2 \%$ \\
$32 \mathrm{~mm}$ & $2.4 \%$ & $2.7 \%$ & $2.9 \%$ \\
\hline \hline
\end{tabular}

given in Table X. In practice, a field flatness of several percent is assumed to be acceptable on the basis of the preliminary IMPACT simulations.

\section{SUMMARY}

All the accelerating-cell frequencies could be tuned to $972.04 \pm 0.08 \mathrm{MHz}$ before brazing [see Figs. 6(d) and 7(b)], which met the required accuracy of $972.04 \pm 0.1 \mathrm{MHz}$.

It can be seen from Fig. 6(d) that reducing the tuning length $d r$ is effective for minimizing the frequency tuning error. In order to reduce $d r$, the prototype half-cell pieces were helpful for this purpose [see Fig. 7(a)].

We attempted to skip the coupling-cell frequency tuning. As a result, the frequencies of T01 and T02 were distributed in the $972.04 \pm 0.26$ (SD) $\mathrm{MHz}$ and $971.88 \pm 0.30$ (SD) $\mathrm{MHz}$ ranges, respectively [the frequency uncertainties are standard deviations (SD) and see Fig. 8]. Although these average frequencies barely met the required accuracy of $971.9 \pm 0.1 \mathrm{MHz}$, the frequency uncertainties of \pm 0.26 and $\pm 0.30 \mathrm{MHz}$ were 3 times as large as the accuracy required for an average frequency of $\pm 0.1 \mathrm{MHz}$. Thus, this result indicates that at least one round of the tuning process is required for the coupling-cell frequencies.

The frequency shift due to brazing for the acceleratingmode frequency ( $+0.16 \mathrm{MHz}$ on average) is still comparable to the required accuracy of $\pm 0.1 \mathrm{MHz}$ (see Table VI, upper). In contrast, the frequency shift due for the coupling mode was $+0.67 \mathrm{MHz}$ on average, which is considerably larger than the expected shift of $+0.10 \mathrm{MHz}$ (see Table VI, bottom). However, the results for the last two modules (buncher 2 and M01) were $0.67 \pm 0.07 \mathrm{MHz}$ (see Tables III and VI). If this trend continues, the expected value of the frequency shift due to brazing, therefore, will be further improved by using experimental data of cavities that will be fabricated in the near future.

At present, from these results, we can conclude that the most reasonable scenario for tuning the accelerating- and coupling-cell frequencies is as follows: (i) Prototype halfcell pieces are fabricated in order to measure their frequencies and coefficients $d f / d r$. Preferably, more than four half cells should be fabricated (two cells equivalent) for improving the reliability of the rf measurement. (ii) The margin for the frequency tuning should be determined while taking into account the frequency deviation due to machining error. From the results of T01, the frequency deviation for the accelerating- and coupling-cell frequencies were typically \pm 0.15 and $\pm 0.4 \mathrm{MHz}$, respectively [see Figs. 6(a) and 8]. One round of frequency tuning is required for the accelerating- and coupling-cell frequencies. (iii) The designed frequencies before brazing have to be determined while taking into account the frequency shift due to brazing. If we use the average of all the measured values, the frequency shifts of the accelerating mode do not seem to be critical for the final frequency tuning error. However, it is difficult to evaluate the 
frequency shift for the coupling mode because of the large frequency shift during brazing. One choice is to use the average of the last two modules as mentioned in Sec. V.

The electric-field distributions measured with the beadpull method were well explained by the coupled resonator model calculation (see Fig. 11). This fact means that the measured frequencies are reliable and that the nonuniform distribution of the on-axis electric field at an operating frequency of $972 \mathrm{MHz}$ is caused by the frequency tuning error of the accelerating tanks.

There were no technical issues involved in brazing and assembly of the present (full-fledged) ACS cavity. This cavity was successfully conditioned up to 1.6 MW (see Fig. 14). This power corresponds to an accelerating field of 4.7 MV/m, which is $10 \%$ higher than the designed value of $4.2 \mathrm{MV} / \mathrm{m}$. This cavity was also conditioned up to 1.6 MW at the frequencies that occurred when its adjustable plungers were positioned at their inward and outward limits. No operating issues, especially those due to a multipactor effect, were observed. This result means that, even though the coupling cells were excited at a certain power level, this cavity could be operated stably.

The present results experimentally demonstrated that the first full-fledged ACS cavity can be fabricated and operated. However, there are still some issues in the couplingcell frequency tuning; in particular, issues caused by the frequency shift due to brazing remain unresolved. At present, the field flatness can be up to $5.0 \%$ due to the frequency shift (see Sec. V). Although this field flatness is assumed to be acceptable on the basis of the IMPACT simulations, the degradation of the field flatness should be minimized as small as possible to maximize the advantage of the ACS, the negligible small dipole component in the accelerating field.

The possibility of reducing the error of the coupling-cell frequency tuning should be examined with a further one or two cavities. As the next step, we plan to fabricate another ACS cavity in order to study and establish the frequency tuning procedure for the future mass production of the ACS modules.

\section{ACKNOWLEDGMENTS}

We would like to thank the members of the J-PARC linac group for fruitful comments and wide-ranging support. Special thanks are due to the staff of Mitsubishi Heavy Industries, Ltd., for manufacturing the cavities.

\section{APPENDIX A: DESIGN OF THE BRIDGE TANK}

A multicavity bridge coupler [15] was adopted for the ACS module. This bridge coupler has a disk-loaded structure, which was operated by a $\pi / 2$ mode. Figure 15 shows the cell geometry of the bridge tank.

The total length of the bridge tank was determined by the length of the drift space between the two accelerating tanks (see Fig. 2). Hence, the length of each cell was

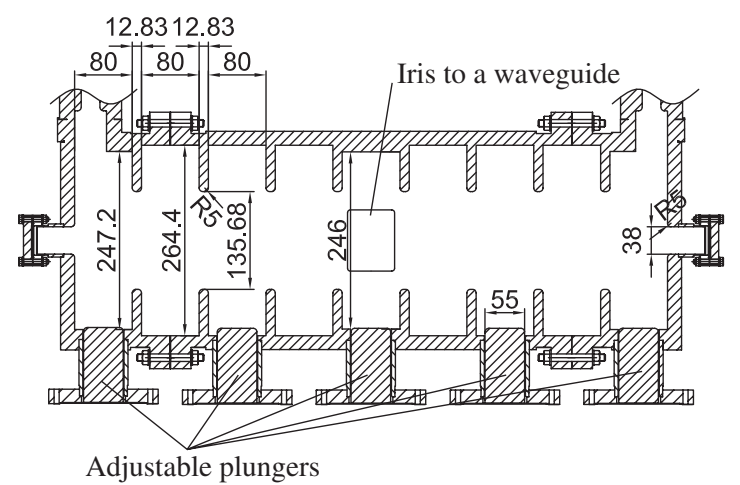

FIG. 15. Cell geometry of the bridge tank.

designed to be $80 \mathrm{~mm}$ and the thickness of each disk was adjusted to be $12.83 \mathrm{~mm}$. The cell diameter was determined to be $264.4 \mathrm{~mm}$, and then an aperture diameter of $135.68 \mathrm{~mm}$ was designed by using SUPERFISH so that the cell frequency was tuned to the operating frequency of 972 MHz. Since both end cells and the center cell have a
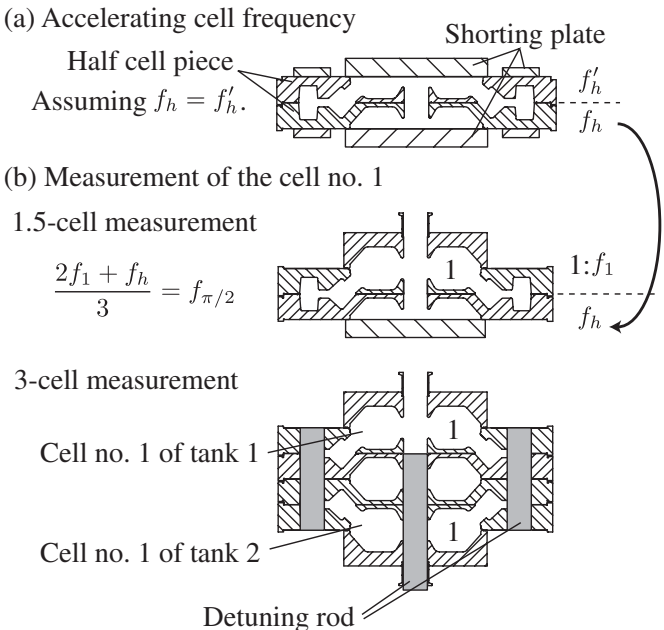

(c) Measurement of the cells no. 1 and no. 33

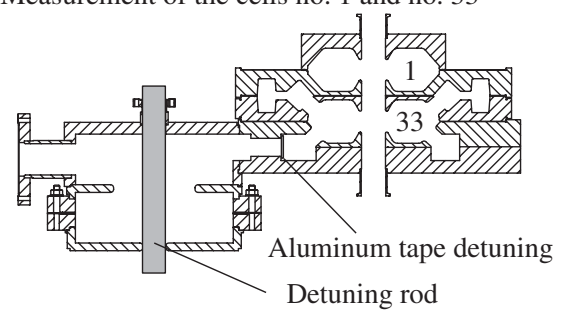

FIG. 16. Measurement procedure of the end cells (number 1 and number 33). (a) The frequencies were measured by a pair of two half-cell pieces using shorting plates. The accelerating-cell frequency was measured for the $\pi / 2$ mode. Here, we assumed that two half-cell frequencies were equal $\left(f_{h}=f_{h}^{\prime}\right)$. (b) In 1.5cell measurement, the number 1 cell is combined with a half-cell piece that has a known frequency. In 3-cell measurement, the end-cell frequency was evaluated by correcting the detuning effect. (c) Cells number 1 and number 33 are stacked to measure the frequency. Here, only the average value was measured. 
coupling slot or an iris to a waveguide, the cell diameter was reduced to compensate the frequency decrease.

\section{APPENDIX B: FREQUENCY TUNING PROCEDURE FOR END CELLS (NUMBER 1 AND NUMBER 33)}

The frequency of end-cell number 1 was evaluated by comparing 1.5-cell and 3-cell measurements. The frequency of a half-accelerating cell $f_{h}$ was measured previously as shown in Fig. 16(a). In 1.5-cell measurement, the end-cell frequency was evaluated by assuming that the resonant frequency of the $\pi / 2$ mode $f_{\pi / 2}$ is the mean of the cell frequencies weighted by the volume of the cell [see Fig. 16(b)]. In 3-cell measurement, the end-cell frequency was evaluated by correcting the detuning effect using MAFIA. By comparing the two results of the 1.5-cell and 3-cell measurements, we determined the lowest frequency as the frequency of the cell number 1. After the frequency tuning of cell number 1 , cell number 33 was machined to tune the average frequency of cells number 1 and number 33 [the setup is shown in Fig. 16(c)] to its target frequency.

\section{APPENDIX C: ESTIMATION OF THE $Q$ VALUE, THE SHUNT IMPEDANCE $Z$, AND $R / Q$ FOR THE ENTIRE MODULE WITH THE BRIDGE TANK}

The stored energy of one excited cell in the bridge tank is $k_{c b} / k_{c a}=(12.3 / 6.63)^{2}=3.44$ times as small as that of an accelerating cell. Here, $k_{c b}$ is the coupling factor between the side-coupling cell and the next excited cell in the bridge tank and $k_{c a}$ is the coupling factor between the sidecoupling cell and the next accelerating cell in the accelerating tank. For M01, the measured values of $k_{c b}$ and $k_{c a}$ were $12.3 \%$ and $6.63 \%$, respectively. The equations used here are described in detail in [8].

Since the accelerating module includes 34 accelerating cells in the two accelerating tanks and five excited cells in the bridge tank, we have

$$
U_{a}: U_{b}=34: \frac{5}{3.44} \quad U_{b}=0.043 U_{a},
$$

TABLE XI. Design parameters of the accelerating tank and the bridge tank.

\begin{tabular}{lcr}
\hline \hline & Accelerating tank & Bridge tank \\
\hline Frequency & $972 \mathrm{MHz}$ & $972 \mathrm{MHz}$ \\
Shunt impedance $Z$ & $44.4 \mathrm{M} \Omega / \mathrm{m}^{\mathrm{a}}$ & \\
$R / Q$ & $7.27 \times 10^{3} \Omega^{\mathrm{b}}$ & \\
$Q$ & $17964^{\mathrm{a}}$ & $23826^{\mathrm{b}}$ \\
\hline \hline
\end{tabular}

${ }^{\mathrm{a}}$ Calculated with MAFIA.

${ }^{\mathrm{b}}$ Calculated with SUPERFISH. where $U$ is a stored energy and the $a$ and $b$ indexes denote the accelerating tank and the bridge tank. Consider the entire stored energy $U$, which can be written by $U=U_{a}+$ $U_{b}=1.043 U_{a}$.

The design parameters of the accelerating tank and the bridge tank are shown in Table XI. When the bridge tank is included, $Z$ and $R / Q$ are lowered by $1 / 1.043=0.959$. Then, we get

$$
\begin{aligned}
& Z=44.4 \times 0.959=42.6(\mathrm{M} \Omega / \mathrm{m}), \\
& R / Q=7.27 \times 10^{3} \times 0.959=6.97 \times 10^{3}(\Omega) .
\end{aligned}
$$

On the other hand, the ratio of $P_{a}$ and $P_{b}$ (where $P$ is the power dissipated in the tank) can be expressed as follows:

$$
P_{b}=P_{a} \frac{U_{b}}{U_{a}} \frac{Q_{a}}{Q_{b}}
$$

Putting the values of $Q_{a}$ and $Q_{b}$ (see Table XI) and Eq. (C1) into Eq. (C2) gives $P_{b}=0.0324 P_{a}$. Consequently, we get

$$
Q=\frac{\omega\left(U_{a}+U_{b}\right)}{P_{a}+P_{b}}=\frac{1+0.043}{1+0.0324} \times 17964=18148 .
$$

[1] V. G. Andreev, V.M. Belugin, V.G. Kulman, E. A. Mirochnik, and B. M. Pirozhenko, in Proceedings of the 1972 Proton Linear Accelerator Conference, Los Alamos, New Mexico, 1972 (Los Alamos Scientific Laboratory of the University of California, Los Alamos, 1972), p. 114.

[2] T. Nishikawa, S. Giordano, and D. Carter, Rev. Sci. Instrum. 37, 652 (1966).

[3] E. A. Knapp, B. C. Knapp, and J. M. Potter, Rev. Sci. Instrum. 39, 979 (1968).

[4] Y. Yamazaki, in Proceedings of the 16th International Linac Conference, Ottawa, Canada, 1992 (Atomic Energy of Canada Limited, Chalk River Laboratories, Ontario, Canada, 1992), p. 520.

[5] T. Kageyama, Y. Morozumi, K. Yoshino, and Y. Yamazaki, in Proceedings of the 16th International Linac Conference, Ottawa, Canada, 1992 (Ref. [4]), p. 456.

[6] J. Billen and L. Young, Los Alamos National Laboratory Report No. LA-UR-96-1834, 1996.

[7] R. L. Sheffield, M. J. Browman, B. E. Carlsten, and L. M. Young, Nucl. Instrum. Methods Phys. Res., Sect. A 318, 282 (1992).

[8] H. Ao and Y. Yamazaki, Phys. Rev. ST Accel. Beams 15, 011001 (2012).

[9] V. V. Paramonov, KEK Report No. 2001-14, 2001.

[10] ANSYS Multiphysics [http://www.ansys.com].

[11] N. Hayashizaki, V. Paramonov, and Y. Yamazaki, in Proceedings of the 21st International Linac Conference, 
Gyeongju, Korea, 2002 (Pohang Accelerator Laboratory, Pohang, Korea, 2002), pp. 752-754.

[12] I. V. Gonin, L. V. Kravchuk, V. V. Paramonov, G. V. Romanov, and A. I. Pedoseev, IEEE Trans. Nucl. Sci. 32, 2818 (1985).

[13] J. Qiang, R. D. Ryne, S. Habib, and V. Decyk, J. Comput. Phys. 163, 434 (2000).
[14] M. Ikegami (private communication).

[15] Y. Morozumi, T. Kageyama, and Y. Yamazaki, in Proceedings of the 1990 Linear Accelerator Conference, Albuquerque, New Mexico, 1990 (Los Alamos National Laboratory, Los Alamos, New Mexico, 1991), p. 153. 